Clearance number AFMC 99-273 ASC 99-1463

\title{
US Air Force Pilot Selection and Training Methods
}

\author{
Thomas R. Carretta, M. S., Ph. D.
}

\begin{abstract}
Carretta, TR. U.S. Air Force pilot selection and training methods. Aviat Space Environ Med 2000; 71: xxx-yyy.
\end{abstract}

Background: US Air Force (USAF) pilot selection and training procedures have changed substantially in the last several years. Pilot selection procedures were augmented with the introduction of computer-based testing to assess pilot aptitude. Training procedures have changed in an effort to modernize the training fleet and provide better, more specialized training earlier in the training process. Results: Despite several studies showing the utility of USAF pilot aptitude tests for predicting training performance, results of a recent policy capturing study suggest that this information is often ignored by pilot candidate selection boards. The two largest sources of USAF pilot trainees relied heavily on measures of officership when making selection decisions. Cumulative research findings suggest that USAF pilot selection decisions could be improved by making better use of currently available personnel attribute data. Further improvements could be expected from the addition of a structured selection interview and measures of personality.

THE KEYWORD IN DESCRIBING U. S. Air Force (USAF) pilot selection and training over the last five years has been "change." Training procedures have changed in an effort to modernize the training fleet and provide better, more specialized training earlier in the training cycle (20). Pilot selection procedures have changed to take advantage of computer-based testing. The purpose of this paper is to review these changes.

\section{Changes in USAF Pilot Training}

\section{Undergraduate Pilot Training (UPT)}

In Undergraduate Pilot Training (UPT), pilot trainees completed primary jet training in the T-37 (21 weeks), then moved on to advanced jet training in the T-38 (32 weeks) (see Figure 1). Near completion of T-38 training an advanced training recommendation board consisting of T-38 instructor pilots evaluated student records and made recommendations for post-UPT 


\section{Report Documentation Page}

Form Approved

OMB No. 0704-0188

Public reporting burden for the collection of information is estimated to average 1 hour per response, including the time for reviewing instructions, searching existing data sources, gathering and maintaining the data needed, and completing and reviewing the collection of information. Send comments regarding this burden estimate or any other aspect of this collection of information,

including suggestions for reducing this burden, to Washington Headquarters Services, Directorate for Information Operations and Reports, 1215 Jefferson Davis Highway, Suite 1204, Arlington

VA 22202-4302. Respondents should be aware that notwithstanding any other provision of law, no person shall be subject to a penalty for failing to comply with a collection of information if it

does not display a currently valid OMB control number.

\begin{tabular}{|c|c|c|}
\hline $\begin{array}{l}\text { 1. REPORT DATE } \\
\mathbf{2 0 0 0}\end{array}$ & $\begin{array}{l}\text { 2. REPORT TYPE } \\
\text { N/A }\end{array}$ & $\begin{array}{l}\text { 3. DATES COVERED } \\
\text { - }\end{array}$ \\
\hline \multirow{3}{*}{\multicolumn{2}{|c|}{ US Air Force Pilot Selection and Training Methods }} & 5a. CONTRACT NUMBER \\
\hline & & 5b. GRANT NUMBER \\
\hline & & 5c. PROGRAM ELEMENT NUMBER \\
\hline \multirow{3}{*}{\multicolumn{2}{|c|}{ 6. AUTHOR(S) }} & 5d. PROJECT NUMBER \\
\hline & & 5e. TASK NUMBER \\
\hline & & 5f. WORK UNIT NUMBER \\
\hline \multicolumn{2}{|c|}{$\begin{array}{l}\text { 7. PERFORMING ORGANIZATION NAME(S) AND ADDRESS(ES) } \\
\text { Air Force Research Laboratory } 2255 \text { H Street Wright Patterson AFB, } \\
\text { OH 45433-7022 }\end{array}$} & $\begin{array}{l}\text { 8. PERFORMING ORGANIZATION } \\
\text { REPORT NUMBER }\end{array}$ \\
\hline \multirow{2}{*}{\multicolumn{2}{|c|}{ 9. SPONSORING/MONITORING AGENCY NAME(S) AND ADDRESS(ES) }} & 10. SPONSOR/MONITOR'S ACRONYM(S) \\
\hline & & $\begin{array}{l}\text { 11. SPONSOR/MONITOR'S REPORT } \\
\text { NUMBER(S) }\end{array}$ \\
\hline
\end{tabular}

12. DISTRIBUTION/AVAILABILITY STATEMENT

Approved for public release, distribution unlimited

13. SUPPLEMENTARY NOTES

The original document contains color images.

14. ABSTRACT

15. SUBJECT TERMS

16. SECURITY CLASSIFICATION OF:

a. REPORT

unclassified b. ABSTRACT

unclassified
17. LIMITATION OF ABSTRACT

$\mathbf{U U}$
18. NUMBER

OF PAGES

13 19a. NAME OF RESPONSIBLE PERSON unclassified 
specialized training assignments in either tanker-transport-bomber (TTB) aircraft or fighterattack-reconnaissance (FAR) air-craft. Specialized training assignments were based on instructor recommendations, student preferences, and aircraft availability.

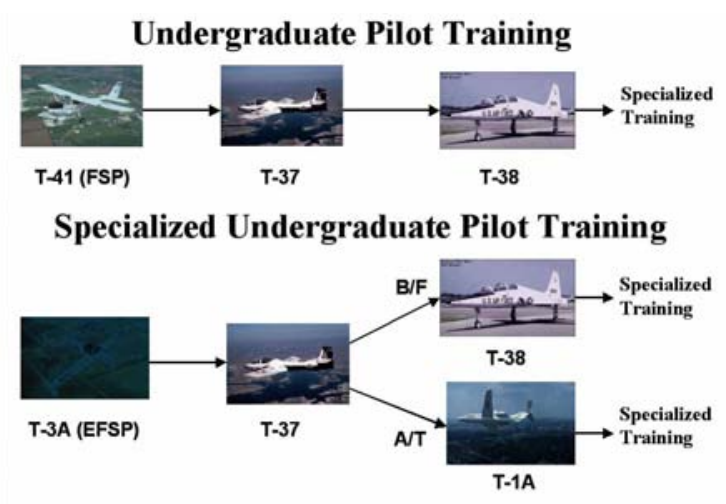

Figure 1. UPT and SUPT Pipelines

\section{Specialized Undergraduate Pilot Training (SUPT)}

UPT was phased out in the mid-1990's and replaced with Specialized Under-graduate Pilot Training (SUPT). Under SUPT, student pilots complete a common T-37 training phase (as in UPT). At the end of T-37 training, students are assigned to one of four advanced training tracks. Most are assigned to either the bomber/fighter $(\mathrm{B} / \mathrm{F})$ or airlift/tanker $(\mathrm{A} / \mathrm{T})$ tracks. A few are assigned to the T-44 advanced turbo-prop or UH-1 helicopter tracks. Track assignments are based on T-37 training performance, aircraft availability, and student preference. B/F training (12) takes place in the T-38 and A/T training (13) takes place in the T-1A, a modified Beech 400 business jet. The T-1 has an impressive electronic flight instrumentation system with pilot configurable multifunction displays, flight management system, weather radar, and electronic displays of maps and checklists.

The reasons for the change to SUPT included the desire to (a) prolong the life of the T38, (b) upgrade the training fleet, and (c) improve training. As not all students would need to go through T-38 training (as in UPT), the life span of the T-38 could be extended. A shortcoming of the generalized flight training provided in UPT was that it did not provide student pilots with specialized skills and knowledge needed to smoothly transition to the large transport and tanker aircraft that constitute one-third of the USAF fleet. With the implementation of T-1 training, A/T students could receive specialized instruction at an earlier stage in their training

Recently, the USAF modified the training sequence for bomber pilots. For a short period starting in late 1998, B-1 and B-52 bomber pilots were selected from among T-1 trained students effectively making the T-38 track a "fighter only" track. More recently, the policy has changed again where B-1 pilots are selected from among T-38 students and B-52 pilots from among T-1 students.

\section{More Changes to Come}


The Air Force goal of upgrading the trainer fleet with current technology aircraft has resulted in decisions to replace the aging T-37 and to upgrade T-38 avionics to contemporary standards. The aircraft chosen to replace the T-37 is the Beech Mk II, known as the Texan II; 2). Student pilot training in the Texan II is expected to begin in 2001. The aircraft will eventually replace all T-37s in SUPT and Euro-NATO Joint Jet Pilot Training (ENJJPT). The flight training syllabus for the Texan II will resemble that used today for T-37 primary training, similar in duration, flight hours, and training events (3).

Modifications to the T-38 will allow the USAF to include mission specific weapons delivery and tactics training in the fighter track. A major avionics upgrade will replace existing T-38 instrumentation commencing in 1999 (1). By 2008, all T-38A and T-38B aircraft used in SUPT and ENJJPT will be upgraded to T-38C configuration.

In addition to the T-38 hardware upgrade, current plans include extending fighter track training by seven weeks to incorporate training now provided in a separate fighter fundamentals course. This potential change is not likely to occur until the T-38C modification has been fully integrated into the force.

\section{Flight Screening Program}

The pre-SUPT Flight Screening Program (FSP) also has changed significantly. Prior to 1994, FSP consisted of about 14 hours instruction in the T-41. In 1994, the T-41 was replaced with the T-3 (Slingsby Firefly) and the hands-on training was extended to 21 hours. This Enhanced Flight Screening Program (EFSP) included more aerobatics training and was popular with students and instructors. However, in July 1997 the T-3 flight operations were suspended following several uncommanded engine stoppages (4).

With the suspension of T-3 training, many students were arriving at SUPT with no handson flying experience. This placed a greater burden on T-37 instructors to get student pilots "up to speed." Even students who had prior flying time in commercial aircraft were sometimes having problems adapting to military flight procedures. Without the benefit of T-3 flight screening, attrition rates for SUPT climbed above 15 percent (4). The USAF considers an 8 to 10 percent attrition rate acceptable.

As a result of the perceived need for pre-SUPT flying training, in October 1998 the USAF implemented an Introductory Flight Training (IFT) program. The IFT program included up to 40 hours flying time in commercial aviation training programs and required a solo flight. The 40-hour IFT program reportedly has produced similar attrition rates in the T-37 phase of SUPT as were observed when EFSP was in use (IFT - 8.8\% vs. EFSP - 7.8\%) (4). In October 1999, the USAF announced plans to implement an expanded IFT program (4). The expanded program will increase hands-on flying time to 50 hours and will require additional solo flights and students to earn a private pilot's license. In the expanded IFT program, students will receive Federal Aviation Administration-certified flight instruction through local flight schools. More than 150 flight schools nationwide may be involved in the training program, mostly near colleges and universities with Air Force Reserve Officer Training Corps (AFROTC) detachments. Pilot candidates at the US Air Force Academy will receive their training in the local area.

After completing the expanded IFT program, pilot candidates will enter SUPT. Although 
T-37 attrition rates have been similar following IFT as were observed following EFSP, some have questioned its utility for USAF training and screening. Skeptics note that IFT is not done in a military context (as was EFSP) and emphasizes training only, not training and screening.

\section{USAF Pilot Selection Methods}

US Air Force pilot qualification standards include medical fitness, anthropometric standards, educational achievement (e.g., college grade point average, major), and for some commissioning sources, aptitude test scores and successful performance in a flight screening program (19). The indicators of pilot aptitude that are used vary by source of commission. Further, although pilot aptitude test scores are used to express qualification minimums for some points of entry, the manner in which these scores are used by selection boards varies $(18,19)$.

\section{Pilot Aptitude Tests}

The two most widely used pilot aptitude tests in the USAF are the Air Force Officer Qualifying Test (AFOQT; 9, 10) and the Basic Attributes Test (BAT; 6, 8). The AFOQT is a 16test paper-and-pencil multiple aptitude battery used for officer commissioning and aircrew selection. It measures general cognitive ability (g), verbal, math, spatial, aviation knowledge, and perceptual speed (10). The AFOQT has been in use since 1957 with new forms developed about every seven years. The 16 tests are combined into five composites: Verbal, Quantitative, Academic Aptitude (Verbal + Quantitative), Pilot, and Navigator-Technical $(9,10)$. The AFOQT Pilot composite consists of eight tests that measure knowledge of aviation and mechanical systems, the ability to determine aircraft attitude from flight instruments, knowledge of aeronautical concepts, ability to read and interpret scales and tables, and spatial ability.

The BAT is a five test computer-based battery used solely for pilot selection. It measures cognitive ability, psychomotor ability, and attitudes toward risk. The BAT was operationally implemented for pilot selection in 1993. Scores from the BAT are combined with the AFOQT Pilot composite and a measure of flying experience to produce a pilot aptitude composite known as PCSM (Pilot Candidate Selection Method; 6, 8). PCSM scores have been shown to be related to probability of completing UPT $(6,7)$, number of flying hours needed to complete training (11), class ranking (7), and fighter qualification (20). Higher PCSM scores are associated with greater probability of completing jet training, fewer hours needed to complete training, higher class rank, and greater likelihood of being fighter qualified. 


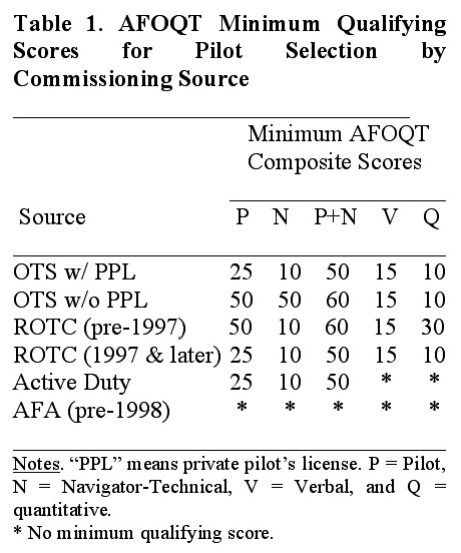

\section{Pilot Selection Standards}

As illustrated in Table 1, the minimum qualifying AFOQT scores for pilot selection vary by commissioning source. The strictest standards are for OTS pilot applicants without a private pilot's license (PPL). The weakest standards are for AFA pilot applicants. The AFA sets no minimum qualifying AFOQT score, instead using it as a "tie breaker" when evaluating pilot applicants (19). There are no established minimum qualifying scores for the BAT or PCSM.

There are seven major points of entry into USAF pilot training (19). These include the Air Force Academy (AFA), Active Duty (AD), Officer Training School (OTS), Reserve Officer Training Corps (ROTC), Air National Guard (ANG), Air Force Reserves, and international pilots. This paper will focus on the first four, as they are the most common sources. Weeks and Zelenski (19) provide a more detailed description.

Air Force Academy (AFA). The AFA requires interested cadets to complete flight screening for qualification prior to meeting a selection board. The AFA pilot selection board consists of six or seven AFA faculty members and a non-AFA representative. All board members are pilots.

Applicant selection folders contain (a) the Cadet Administration Management Information System (CAMIS) sheet, (b) evaluations by AFA faculty members, and (c) an optional letter by the pilot candidate. The CAMIS sheet provides detailed information on: personnel data, academic, military, and athletic performance, honors, flight screening performance, participation in airmanship and aviation courses, involvement in clubs, probation history, and AFOQT scores (not required for qualification). No explicit gender or race/ethnicity information is provided.

Active Duty (AD). Active duty officers may apply for pilot training through the Air Force Personnel Center (AFPC). Qualification is based on age, medical, and anthropometric standards and minimum qualifying AFOQT scores. The AD pilot selection board consists of the AFPC Vice Commander, an AFPC colonel, and two lieutenant colonels that are current or former flying squadron commanders.

The AD selection board process is similar to that used by the AFA and OTS. Board 
members are instructed to use a "whole person" concept. The relative importance of selection factors is not prescribed, but is left up to the individual board members. Board members attempt to reach a consensus on the evaluation of each record. When divergent ratings occur, they are resolved by rescoring applicants records.

Application folders contain an Officer Application for Flying Training, Officer Performance Reports (OPRs), training reports, citations accompanying military decorations, a career brief, and the PCSM score. Unlike the AFA, AD selection folders contain explicit information about applicants' gender and race/ethnicity.

Officer Training School (OTS). As a group, OTS pilot applicants tend to be older than other USAF pilot applicants, are college graduates, and may have significant civilian flying experience. Many have prior military experience, typically as active duty Air Force enlisted members. OTS pilot selection boards consist of three pilots (colonels or colonel-selects).

Compared with other commissioning sources, OTS pilot applicant folders contain the most comprehensive set of information. As with the AFA and Active Duty, board members are instructed to use a "whole person" approach. Board members are provided a scoring policy that suggests the relative importance of three broad categories of information: (a) "experience" (civilian or military employment, outside activities; 0-3 points), (b) "education and aptitude" (academic history, AFOQT, PCSM; 0-3 points), and (c) potential and adaptability" (recommendations; 0-4 pints). As with Active Duty boards, divergent ratings are resolved by rescoring applicant records.

Selection folders include aptitude test scores (i.e., AFOQT and PCSM), biographical and educational information, employment history, history of legal violations, civilian flying records including flying and FAA medical certificates, letters of recommendation, and other data. As with Active Duty selection procedures, OTS selection boards are provided explicit information about candidates' gender and race/ethnicity.

Reserve Officer Training Corps (ROTC). ROTC pilot applicants are cadets in their junior year of college. There are nearly 150 college and university ROTC detachments that can provide applicants. A centralized board consisting of rated field grade officers from HQ AFROTC at Maxwell AFB makes pilot candidate selection decisions.

The process of categorizing ROTC pilot applicants is different from that used by the other commissioning sources. Board members are not required to manually review the detailed contents of folders. The ROTC pilot selection process is supported by preprocessing of applicant data to create a preliminary rank-order of applicants. As a result, the workload for ROTC board members is minimized and the relative importance of selection factors is the same for all applicants.

The algorithm that supports ROTC pilot candidate selection weights selection factors to create a composite known as the Categorization Order of Merit (COM) score. The information that contributes to the COM score includes an evaluation of the cadet's officer potential by the detachment commander (i.e., Relative Standing Score), college grade point average, AFOQT composite scores, and a physical fitness test score. It is interesting to note that prior civilian flying experience does not contribute to the COM score. Prior to 1998, the PCSM score also did 
not contribute to the COM score.

Cadets are rank-ordered from highest to lowest based solely on COM score. The pilot production requirement is applied to produce an initial cut line. The selection board then reviews the list considering all information presented. It may accept the rank-ordered list as presented or adjust the ordering on the basis of selection criteria independent of the COM score (e.g., ROTC detachment, gender, race/ethnicity, previous flying experience, field training awards, academic major).

\section{Selection Ratios}

The proportion of applicants selected for pilot training varies by point of entry and as a function of the needs of the US Air Force (i.e., annual pilot production quotas). Over the last several years, most pilot candidates have come from the AFA and ROTC. In contrast, OTS selection boards have been very selective during a period of low pilot production. For example, in 1996 the pilot selection ratios were .789 (375/475) for the AFA, .147 (81/551) for Active Duty, .047 (16/340) for OTS, and .711 (382/537) for ROTC (16). The combined selection ratio for all four sources was $.449(854 / 1,903)$.

\section{USAF Pilot Selection Board Policy Capturing Study}

The USAF recently conducted a policy capturing exercise to better understand the process by which the AFA, Active Duty, OTS, and ROTC pilot selection boards made

their decisions $(18,19)$. Policy capturing involves quantifying the process used by a decisionmaker through which informational

attributes are weighed and combined to make a decision. Results for Active Duty and OTS boards should be viewed as preliminary due to the small number of pilots produced from those commissioning sources.

The policy capturing method used was the same for each point of entry. The only differences were in the information available in the applicants' folders and the timeframe for the data collection. So, rather than describing the policy capturing method separately for each, it is described only for the AFA. The AFA provided applicant folders and average board ratings for the 1995, 1996, and 1997 classes. Research team members observed the selection board process and surveyed board members to identify the most important attributes. A database was constructed and a series of linear regression analyses were performed to determine which applicant variables were actually used by selection boards. Applicant information was used as the independent variables and average board rating was the dependent variable. Using input from selection board members, relevant applicant attributes were selected and included in a preliminary "baseline" selection policy model. Variables that were highly significantly correlated with average board rating were retained and those that were not were discarded. Once a model was determined for a specific board for a specific year, it was applied to the following yearly boards to evaluate the stability of the policy model across boards. For the AFA, selection policy models were developed for 1995, 1996, and 1997, and a general model was developed for all years combined.

The yearly AFA pilot selection board policy capturing models showed great consistency 
from year to year, with no statistically significant differences between the separate yearly models. The general model (across years) showed a very good fit, accounting for $90 \%$ of the variability in board ratings $\left(\mathrm{R}^{2}=.90\right)$. Results indicated a heavy reliance on cumulative military performance average, cumulative grade point average, and flight screening performance. Variables that contributed to a lesser extent to the AFA policy capturing model were: participation in a varsity sport, whether or not the applicant had held a commander military position, and whether or not the cadet had held a lower military position in their senior year. "Officership" as indicated by military performance was more important for pilot selection decisions than was ability as measured by cumulative grade point average and flight screening performance rating. AFOQT scores were given little importance and were used mainly as a "tie breaker" for distinguishing among candidates close to the "cut line."

For Active Duty pilot selection boards, separate policy capturing analyses were done for non-rated line officers and navigators for fiscal years 1996 and 1997. In each case, the resultant general (combined fiscal years) policy capturing model showed a good fit $\left(\mathrm{R}^{2}=.78\right.$ and .72 respectively). For non-rated line officers, the most important selection factor by far was PCSM. Variables that contributed to a lesser extent to the non-rated model were: $2^{\text {nd }}$ lieutenant rank, positive endorser's recommendation, possession of an engineering or mathematics degree, possession of a master's degree, and possession of a flying instrument's rating.

For Active Duty navigators, the most important selection factors were PCSM and the AFOQT Quantitative composite. Positive endorser's recommendation and positive commander's recommendation contributed to a lesser extent.

OTS selection boards provided applicant folders and average board ratings for the first and second quarters of fiscal year 1996. The general (combined quarters) OTS pilot selection board policy capturing model showed a relatively poor fit $\left(\mathrm{R}^{2}=.51\right)$ compared with results from the other points of entry. The relatively poor fit was probably due to the small number of applicants selected. The most important factors were college grade point average and PCSM score. Number of recommendation letters, interviewers' recommendations, number of moving traffic violations, and possession of a bachelor of arts degree contributed to a much lesser extent to the OTS policy capturing model.

For the ROTC, the COM score was by far the most important factor in pilot candidate selection. Very few candidates were re-ordered on the basis of non-COM data. As a result, no formal policy capturing study was conducted $(18,19)$. Instead, analyses focused on understanding the relative importance of the COM components in determining the overall COM score. Examination of the weights and upper and lower bounds of the COM components revealed that the commander's assessment of the cadet's officer potential (Relative Standing Score or RSS) accounted for about $47.8 \%$ of the variability in the COM score. The other COM components accounted for the remaining $52.2 \%$ as follows: college grade point average (19.8\%), physical fitness test score $(11.5 \%)$, AFOQT Verbal composite (11.5\%), and AFOQT Quantitative composite (9.4\%).

Examination of Pearson correlation coefficients between the COM score and its components provided another way of looking at the relative importance of the COM components $(18,19)$ in determining overall COM score. As in the analysis of the COM weights, RSS had the strongest relationship with overall COM score. The correlations between COM and its 
components were: RSS (.921), college grade point average (.639), physical fitness test score (.437), AFOQT Verbal composite (.290), and AFOQT Quantitative composite (.325). These results taken together clearly showed that RSS was the most influential determinant of the overall COM score, and as a result, ROTC pilot selection decisions. Pilot aptitude measures such as PCSM or previous flying experience were virtually ignored in the ROTC pilot selection process.

The two largest sources of USAF pilots (AFA and ROTC) place a much greater emphasis on measures of officership (AFA - military performance average, ROTC - RSS) than measures of ability (e.g., academic performance, flight screening performance, aptitude test scores) when selecting pilot trainees. This is rather perplexing in the absence of studies showing validity for measures of officership for predicting pilot training performance.

Weeks (18) reported a study of the relative predictive utility of officership as measured by the RSS and ability as measured by the AFOQT Pilot composite for 469 ROTC cadets who attended undergraduate pilot training. The correlation between RSS and pass/fail training was .01 (ns), whereas the correlation between AFOQT pilot composite and pass/fail training was .14 ( $\mathrm{p}<$ .01). These analyses indicate almost no relationship between officership ratings and pilot training attrition. The strength of the relationship between ability and pilot training outcome is lower than usually reported (see for example, 8, 9), but still clearly shows that ability represents an improvement over officership ratings for selection.

\section{Validity of PCSM for T-37 Training}

Operational PCSM testing began in June 1993 and selection boards first received PCSM scores in December 1993. Air Education and Training Command Studies and Analyses Squadron (AETC/SAS) subsequently conducted an evaluation of

PCSM in June 1997 (16). At the time of the evaluation, 7,057 USAF pilot training applicants had valid PCSM scores (had tested on the AFOQT and BAT). Of these, 1,276 had been selected and entered pilot training; 676 either had been eliminated from training or had successfully completed T-37 training. The T-37 graduation rate was 81.2\% (549/676). Ness (16) did not report the correlation between PCSM and the dichotomous pass/fail training outcome, but reported the pass rate for trainees grouped by PCSM score (1-25, 26-50, 51-76, and 76-99). The T-37 pass rates for the four groups were: 1-25: 58.4\% (66/113); 26-50: 69.7\% (83/119); 51-75: 82.4\% (103/125); and 76-99: 93.1\% (297/319). Ness (16) observed that pilot trainees with PCSM scores of 50 or lower were much less likely to complete T-37 training than were those with scores greater than 50 (64.2\% vs. $90.1 \%$ pass rate). Based on these results, he recommended that a minimum PCSM score of 50 be adopted and that PCSM be extended to the AFA.

In a further breakout of PCSM scores for the 676 pilot trainees, Ness (16) displayed the number of trainees with scores of 1-25, 26-50, 51-75, and 76-99 for each commissioning source that tested their pilot applicants on PCSM (AD, OTS, and ROTC). Almost all AD and OTS pilot trainees had PCSM scores greater than 50, with most scores greater than 75. In contrast, ROTC pilot trainees were nearly equally likely to have scores in any of the four PCSM groups (1-25, 26-50, 51-75, and 76-99). This is consistent with the pilot selection board policy capturing study results $(18,19)$ that AD and OTS selection boards relied on PCSM in their selection process and ROTC boards did not. 
A second examination of the utility of PCSM was conducted for this paper in order to get an estimate of its validity against T-37 outcome. As of Fall 1998, 1,268 USAF pilot trainees with PCSM scores had completed the T-37 phase of SUPT. The T-37 graduation rate was $80.1 \%$ (1,016/1,268; see footnote 6). As observed in the AETC/SAS PCSM evaluation (16), examination of the PCSM scores for these trainees clearly showed that some selection boards did not use the PCSM score. The mean PCSM percentile score was 62.8 and ranged from 1 to 99 . Two hundred twenty-nine (18.1\%) of the trainees had PCSM scores of 25 or lower. Twenty-three $(1.8 \%)$ had PCSM scores of 1.

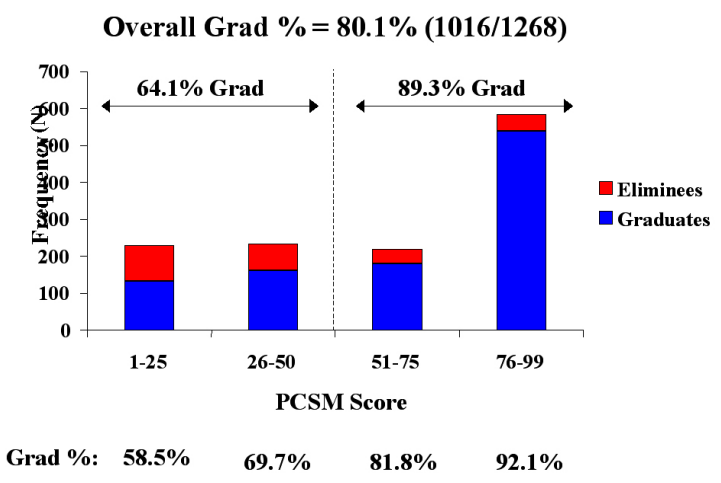

The observed correlation between PCSM and the dichotomous pass/fail T-37 training criterion was .335 . The correlation increased to .479 after correction for dichotomization of the training criterion. As shown in Figure 2, higher PCSM scores were clearly related to greater probability of successfully completing T-37 training. The pass rates for the four groups were: 125: 58.5\% (134/229); 26-50: 69.7\% (163/234); 51-75: 81.8\% (180/220); and 76-99: 92.1\% (539/585). As noted earlier, AD, OTS, and ROTC currently set minimum qualifying AFOQT Pilot composite scores for pilot training with values of either 25 or 50 (see Table 1). If a minimum qualifying PCSM score of 25 had been used, the overall T-37 training pass rate would have been about $84.5 \%(882 / 1,039)$ instead of the observed $80.1 \%(1,016 / 1,278)$. Had a minimum qualifying PCSM score of 50 been used, as suggested by Ness (16), the T-37 training pass rate would have been about 89.3\% (719/805). Results from both Ness (16) and the current study clearly show that establishment of a minimum PCSM score consistent with current AFOQT minimum scores for pilot training qualification could help reduce training attrition.

\section{Final Thoughts}

Current AETC efforts are focusing on upgrading the BAT hardware and test battery. AETC has begun the work needed to replace the original 386-based systems with Pentium-based systems and to evaluate candidate replacement BAT tests.

Cumulative research findings suggest that USAF pilot selection decisions could be improved simply by making better use of currently available personnel attribute data. Higher PCSM scores are associated with greater probability of completing jet training $(6,7,16)$, fewer flying hours needed to complete training (11), higher class rank (7), and greater likelihood of being fighter qualified (20). Despite this, to date no minimum qualifying PCSM score has been 
adopted. The reason for this is unclear. It appears that the various commissioning sources are reluctant to give up any autonomy they currently have in setting pilot selection policy. However, the PCSM program has been extended till 2003. AETC/CC has directed the use of PCSM in all pilot candidate boards. As of March 1999, all have implemented PCSM except the AFA. In 1998, ROTC modified the COM equation removing the AFOQT Pilot composite and replacing it with the PCSM score (14). The effectiveness of this modification for reducing pilot training attrition will depend on the relative weight assigned to the new COM components.

Results from recent studies in personnel selection and occupational performance provide some clues as to how personnel attribute data can be better integrated into the pilot selection process $(8,15,17)$. The validity of PCSM has been shown to come mostly from the measurement of cognitive ability, psychomotor ability, pilot job knowledge, and flying (i.e., jobrelated) experience (8). This is consistent with results from a large-scale meta-analysis of the validity and utility of selection methods for training and job performance across a variety of occupations (17). Schmidt and Hunter (17) estimated the predictive validity of general mental ability (GMA) tests to be .56 for training. The two combinations of predictors with the highest multivariate validity for job training programs were GMA plus an integrity test (mean validity of .67) and GMA plus a conscientiousness test (mean validity of .65). For job performance, the predictive validity of GMA tests was estimated to be .51 and was incremented by the addition of a work sample test (.63), a structured interview (.63), an integrity test (.65), or a conscientiousness test (.60). Similarly, McHenry, Hough, Toquam, Hanson, and Ashworth (15) reported that measures of temperament/personality were incremental to cognitive measures for predicting US Army training criteria reflecting "effort and leadership," "personal discipline," and "physical fitness and military bearing." McHenry et al.'s (15) results suggest that measures of temperament/personality might be useful for officer selection, which is closely tied to pilot selection in the USAF, as pilot applicants must first be accepted for officer commissioning (19).

To reiterate, the effective use of currently available personnel attribute data could lead to cost avoidance savings due to reduced training attrition (16) and the requirement for fewer hands-on flying training hours (11). Results from studies of personnel selection and occupational performance $(15,17)$ suggest that the validity and utility of current USAF pilot selection methods (i.e., selection boards, PCSM) could be enhanced by the introduction of a structured selection interview and measures of personality.

\section{ACKNOWLEDGMENTS}

The opinions expressed are those of the author and are not necessarily those of the United States Government, the Department of Defense, or the United States Air Force. The author thanks Dr. Joseph L. Weeks and Maj. Warren E. Zelenski for their contributions to this effort. Address correspondence to Dr. Thomas R. Carretta, AFRL/HECI, Area B, Bldg. 146, Room 122, Wright-Patterson AFB, OH 45433-7511. Send e-mail to thomas.carretta@wpafb.af.mil.

\section{REFERENCES}

1. Air Education and Training Command. Systems Requirements Document for T38 avionics upgrade program, avionics subsystem, and avionics support subsystems. 


\section{Randolph AFB TX: AETC/XORF 1995.}

2. Air Education and Training Command and Chief of Naval Training. Aircraft System Require- ments Document (SRD) for the Joint Primary Aircraft Training System. Randolph AFB TX: AETC/XORF, and Pensacola NAS FL: CNATRA N34B 1994a.

3. Air Education and Training Command and Chief of Naval Training. Syllabus of instruction for Joint Undergraduate Primary Pilot Training (JPPT). Randolph AFB TX: AETC/XORF, and Pensacola NAS FL: CNATRA N34B 1994b.

4. Air Force News. AF replaces T-3 flying program. http://www.af.mil/ news/Oct1999/n19991012_991881. html. Washington, DC: AFPN 13 October 1999.

5. Carretta TR. Basic Attributes Test (BAT) system: The development of an automated test battery for pilot selection. Brooks AFB, TX: Air Force Human Resources Laboratory, Manpower and Personnel Division, AFHRL-TR-1987; 87-9.

6. Carretta TR. Recent developments in U. S. Air Force pilot candidate selection and classification. Aviat Space Environ Med 1992a; 63:1112-4.

7. Carretta TR. Understanding the relations between selection factors and pilot training performance: Does the criterion make a difference? Int J Aviat Psych 1992b; 2:95-105.

8. Carretta TR, \& Ree MJ. Pilot candi-

date selection method (PCSM):

Sources of validity. Int J Aviat Psych

1994; 4:103-117.

9. Carretta TR, Ree MJ. Air Force

Officer Qualifying Test validity for

predicting pilot training performance.

J Bus Psych 1995; 9:379-88.

10. Carretta TR, Ree MJ. Factor structure of the Air Force Officer Qualifying Test: Analysis and comparison. Mil Psych 1996; 8:29-42.

11. Duke AP, Ree MJ. Better candidates fly fewer training hours: Another time testing pays off. Int J Select Assess 1996; 4:115-21.

12. Headquarters $19^{\text {th }}$ AF. Syllabus of instruction: Specialized Undergraduate T-38 Pilot Training (19 ${ }^{\text {th }}$ AF Syllabus P-V4A-A (T-38)). Randolph AFB, TX: 619 TRSS/IDF 1995a.

13. Headquarters $19^{\text {th }}$ AF. Syllabus of instruction: T-1A Joint Specialized Undergraduate Pilot Training (19 ${ }^{\text {th }}$ AF Syllabus P-V4-A-G). Randolph AFB, TX: 619 TRSS/IDT $1995 \mathrm{~b}$. 
14. Headquarters Air Force Reserve Officer Training Corps. AFROTC allocations management. Maxwell AFB, AL: AFROTCI 36-2013 31 January 1998.

15. McHenry JJ, Hough LM., Toquam JL., Hanson MA, Ashworth S. Project A validity results: The Relationship between predictor and criterion domains. Pers Psych 1990;

43:335-354.

16. Ness G. Pilot Candidate Selection Method (PCSM) evaluation (Issue Brief). AETC Studies and Analyses Squadron, Randolph AFB, TX 1997.

17. Schmidt FL, Hunter J.E. The validity and utility of selection methods in personnel psychology: Practical and theoretical implications of 85 years of research findings. Psych Bull 1998; 124:262-274.

18. Weeks JL. USAF pilot selection. Mesa, AZ: Air Force Research Laboratory, Warfighter Training Research Division. AFRL-HE-AZ-TP-2000; 00-4.

19. Weeks JL, Zelenski WE. Entry to USAF undergraduate flying training. Brooks AFB, TX: Air Force Research Laboratory, Warfighter Training Research Division, AFRL-HE-AZ-TR1998; 1998-77.

20. Weeks JL, Zelenski WE, Carretta TR. Advances in USAF pilot selection. Selection and Training Advances in Aviation (AGARD-CP-588). Prague, Czech Republic 1996; 1-1-1-11. 